\title{
RUANG KETIGA DAN KONSEP KONTEKSTUAL PERANCANGAN RUANG SENI DI SENEN
}

\author{
Fille Tamalazare Yuma ${ }^{1)}$, Maria Veronica Gandha ${ }^{2)}$
}

1)Program Studi S1 Arsitektur, Fakultas Teknik, Universitas Tarumanagara, tz.tamala@gmail.com

2)Program Studi S1 Arsitektur, Fakultas Teknik, Universitas Tarumanagara, mariag@ft.untar.ac.id

\begin{abstract}
Abstrak
Pada era yang serba modern hilangnya third place pada pusat kota seperti kota Jakarta mengakibatkan pusat perbelanjaan semakin menjamur dan market gimmick yang terus meningkat. Hal tersebut menyebabkan tingkat interaksi sosial antara sesama manusia menurun sehingga terbentuklah eksklusifitas pada setiap individu. Dalam pemenuhan kebutuhan sosial di era tersebut, maka dibutuhkan wadah sosial sebagai wadah komunitaskomunitas untuk menghilangkan ekslusifitas dan mengembalikan hakekat manusia yang pada dasarnya adalah mahluk sosial yang perlu berinteraksi. Dari hal tersebut, arsitektur berbicara tentang cara untuk memenuhi kebutuhan komunitas pada third place sebagai sarana eksistensi masyarakat. Kehadiran Art Space dimaksudkan untuk menghadirkan komunitaskomunitas di mana individu dapat melebur dan meningkatkan interaksi sosial. Art Space mengangkat topik seni yang merupakan salah satu karakteristik kawasan Kelurahan Senen, Kecamatan Senen, Jakarta Pusat. Seni akan digunakan sebagai media dan alat untuk berinteraksi serta berkomunikasi antara sesama manusia. Menjadikan pusat hiburan seni yang inklusif sehingga dapat dinikmati oleh seluruh golongan masyarakat baik seniman, penikmat seni atau khalayak umum. Pemilihan jenis seni pertunjukan didasarkan oleh tingginya animo masyarakat pada Kelurahan Senen. Perancangan Art Space didesain dengan metode site analysis agar bangunan memperhatikan konteks sekitar sehingga memperkuat konsep kontekstual. Mengkombinasikan tipologi yang diadaptasi dari kebiasaan atau pendekatan kebutuhan masyarakat sekitar. Meleburkan batasan diantara private closeness dan public opensess. Diharapkan Art Space dapat menarik masyarakat untuk berkunjung sehingga menghadirkan interaksi sosial.
\end{abstract}

Kata kunci: Art Space; Interaksi Sosial; Third Place

\begin{abstract}
In the modern era, the loss of third place in the city center, such as the city of Jakarta, has resulted in increasingly mushrooming shopping centers and increasing market gimmicks. This causes the level of social interaction between fellow humans decreases so that exclusivity is formed in each individual. In meeting social needs in that era, a social forum is needed as a place for communities to eliminate exclusivity and restore human nature which is basically a social creature that needs to interact. From this, architecture talks about ways to meet the needs of the community in the third place as a means of community existence. The presence of Art Space is intended to present communities where individuals can fuse and increase social interaction. Art Space raised the topic of art which is one of the characteristics of the Senen Kelurahan, Senen District, Central Jakarta. Art will be used as a medium and a tool to interact and communicate with each other. Making an entertainment center for art that is inclusive so that it can be enjoyed by all groups of people both artists, connoisseurs of art or the general public. The choice of performing arts is based on the high public interest in the Senen Village. The design of Art Space is designed with site analysis method so that the building pays attention to the surrounding context so as to strengthen the contextual concept. Combining typologies adapted from the habits or approaches of the needs of the surrounding community. Bluring boundaries between private closeness and public opensess. It is expected that Art Space can attract people to visit so that it presents social interaction.
\end{abstract}

Keywords: Art Space; Social Interaction; Third Place 


\section{PENDAHULUAN}

Masyarakat kota cenderung mencari hiburan atau bertemu dengan teman di pusat perbelanjaan. Pada kondisi ini menjamurnya program komersil diiringi dengan perkembangan teknologi membuat manusia terbagi ke dalam segmen-segmen yang semakin eksklusif. Hilangnya unsur interaksi antar sesama akibat banyaknya atraksi dan market gimmick. Interaksi sangatlah diperlukan manusia untuk membina rasa empati, kepedulian, daya nalar, proaktif dan hal -hal lain terhadap sesama manusia. Karena itu the third place diperlukan. Third place merupakan ruang antara sebagai tempat komunitas. Mewadahi kebutuhan aktivitas masyarakat sekitar untuk meningkatkan interaksi sosial manusia dan menumbuhkan aspek humanis, terbuka, dinamis serta proaktif.

Open architecture menjadi peluang untuk menciptakan sebuah platform arsitektur yang dapat dikombinasikan dengan berbagai macam keadaan dan kondisi masyarakat dalam hal ini masyarakat perkotaan Jakarta atau kota besar lainnya. Adapun maksud dari proyek ini adalah untuk menghadirkan ruang interaksi secara langsung. Secara lebih spesifik, kehadiran proyek menghadirkan komunitas-komunitas. Menggunakan media seni sebagai alat untuk berkomunikasi dan berinteraksi antar sesama. Hal ini diangkat atas dasar kekhawatiran masyarakat kota yang terpecah ke dalam segmen-segmen yang semakin eksklusif. Diharapkan melalui proyek ini manusia dapat melakukan refleksi terhadap dirinya sendiri dan menyadari bahwa pada hakikatnya, dirinya adalah makhluk sosial yang saling membutuhkan. Art Space membebaskan seluruh lapisan masyarakat untuk berkunjung ke setiap bagian secara gratis. Terbukanya akses terhadap berbagai pertunjukan seni.

\section{KAJIAN LITERATUR}

Open Architecture, merupakan third place bagi masyarakat kota yang berfungsi sebagai ruang antara, bukan tempat tinggal (rumah) dan bukan tempat kerja, melainkan suatu tempat untuk melepas penat dari aktivitas sehari-hari. Third place adalah program yang akan membantu masyarakat kota agar bersifat humanis, terbuka, dinamis dan produktif. . ${ }^{[1]}$ Open architecture merupakan sistem yang terbuka dan mampu beradaptasi dengan kepentingan terpilih (selected), Konflik-konfik yang terjadi dari masyarakat kota dapat di pecahkan atau dilakukan pendekatan melalui rangkaian pendekatan disain dan juga strategi perancangan.

Third place di dalam konteks kota dimana didalamnya terdapat program utama yang didukung oleh program -program lain yang mampu melayani kebutuhan masyarakat kota modern yang menuntut kehidupan yang serba cepat, dinamis dan efisien yang kemudian diajukan sebagai proposal arsitektur yang dinamakan Open Architecture. Open Architecture sebagai third place dapat didefinisikan dengan melihat hal-hal penting yang terkait dengan konteks kebutuhan masyarakat kota dan modernitas yang berorientasi pada teknologi, informasi dan individu.

Oldenburg menyebut "first place" rumah dan tempat tinggal seseorang. "second place" adalah tempat kerja di mana orang mungkin menghabiskan sebagian besar waktu mereka. Maka, third place adalah tempat kehidupan komunitas yang memfasilitasi dan mendorong interaksi sehingga lebih luas dan lebih kreatif. Dengan kata lain, Third place adalah di mana Anda bersantai di depan umum, di mana Anda berjumpa dengan wajah-wajah yang akrab dan berkenalan baru. Pandangan Oldenburg tentang tempat ketiga dengan delapan karakteristik:

a. Tapak bersifat netral

Penghuni third place memiliki sedikit atau tidak ada kewajiban untuk berada di sana. Mereka tidak terikat ke daerah itu secara finansial, politik, hukum, atau sebaliknya dan bebas untuk datang dan pergi sesuka mereka.

b. Tempat menyamaratakan

Third Place tidak mementingkan status individu dalam suatu masyarakat. Status ekonomi atau sosial seseorang tidak penting di tempat ketiga, memungkinkan rasa kesamaan di 
antara penghuninya. Tidak ada prasyarat atau persyaratan yang akan mencegah penerimaan atau partisipasi di Third Place.

c. Percakapan adalah kegiatan utama

Obrolan menyenangkan dan bahagia adalah fokus utama dari aktivitas third place, meskipun tidak harus menjadi satu-satunya aktivitas. Nada percakapan biasanya ringan dan lucu kecerdasan dan sifat main-main yang baik sangat dihargai.

d. Aksesibilitas dan akomodasi

Third place harus terbuka dan mudah diakses oleh mereka yang menempatinya. Mereka juga harus akomodatif, artinya mereka memenuhi kebutuhan penghuninya, dan semua penghuni merasa kebutuhan mereka telah terpenuhi.

e. Para pelanggan tetap

Third place memiliki sejumlah pengunjung tetap yang membantu memberi ruang nada, dan membantu mengatur suasana hati dan karakteristik daerah. Reguler ke tempat ketiga juga menarik pendatang baru, dan ada di sana untuk membantu seseorang yang baru ke ruang merasa diterima dan ditampung.

f. Low profile

Third place secara karakteristik sehat. Bagian dalam tempat ketiga adalah tanpa pemborosan atau kebesaran, dan memiliki perasaan yang sederhana. Tempat ketiga tidak pernah sombong atau sok, dan menerima semua jenis individu, dari berbagai lapisan masyarakat.

g. Moodnya menyenangkan

Nada percakapan pada third place tidak pernah ditandai dengan ketegangan atau permusuhan. Sebaliknya, third place memiliki sifat yang menyenangkan, di mana percakapan cerdas dan olok-olok sembrono tidak hanya umum, tetapi sangat dihargai.

h. Jauh dari rumah

Penghuni third place akan sering memiliki perasaan hangat, kepemilikan, dan kepemilikan yang sama seperti di rumah mereka sendiri. Mereka merasa sepotong diri mereka berakar di ruang, dan mendapatkan regenerasi spiritual dengan menghabiskan waktu di sana.

\section{Seni dalam konteks Open Architecture}

Seni juga dapat diartikan dengan sesuatu yang diciptakan manusia yang mengandung unsur keindahan. Seni adalah suatu cara dari diri kita sendiri untuk berkomunikasi atau berekspresi, yang mungkin tidak dapat kita ungkapkan dengan kata-kata dan bisa dengan musik, bisa dengan lukisan, bisa dengan tarian sesuai dengan ciri khasnya. Seni dapat digunakan sebagai alat komunikasi seperti pesan, kritik sosial, kebijakan, gagasan, dan memperkenalkan produk kepada masyarakat. Melalui media seni tertentu seperti, wayang kulit, wayang orang dan seni teater, dapat pula syair sebuah lagu yang mempunyai pesan, poster, drama komedi, dan reklame. Seni yang berfungsi sebagai sarana melepas kejenuhan atau mengurangi kesedihan, Sebuah pertunjukan khusus untuk berekspresi atau mengandung hiburan, kesenian yang tanpa dikaitkan dengan sebuah upacara ataupun dengan kesenian lain.

\section{Seni dalam konteks Hiburan}

Seni pertunjukan merupakan suatu bentuk sajian pentas seni yang diperlihatkan atau dipertunjukan kepada khalayak umum atau orang banyak oleh pelaku seni (seniman) dengan tujuan untuk memberikan hiburan yang dapat dinikmati oleh para penontonnya. Hiburan selalu bersifat menyenangkan, karena hiburan bersifat menghibur seseorang setelah melakukan aktifitas atau rutinitasnya sehari-hari agar bisa menghilangkan penat dan lelah selama bekerja. Seni pertunjukan adalah kegiatan di luar kegiatan kerja sehari-hari. Seni dan kerja dipisahkan. Seni adalah kegiatan di waktu senggang yang berarti kegiatan diluar jam-jam kerja mencari nafkah. Seni merupakan kegiatan santai untuk mengendorkan ketegangan akibat kerja keras mencari nafkah (Sumardjo, 2001:2). 


\section{Jenis Kegiatan seni dan kebutuhan ruang}

Tabel 1. Kebutuhan Ruang Berdasarkan Aktivitas Seni

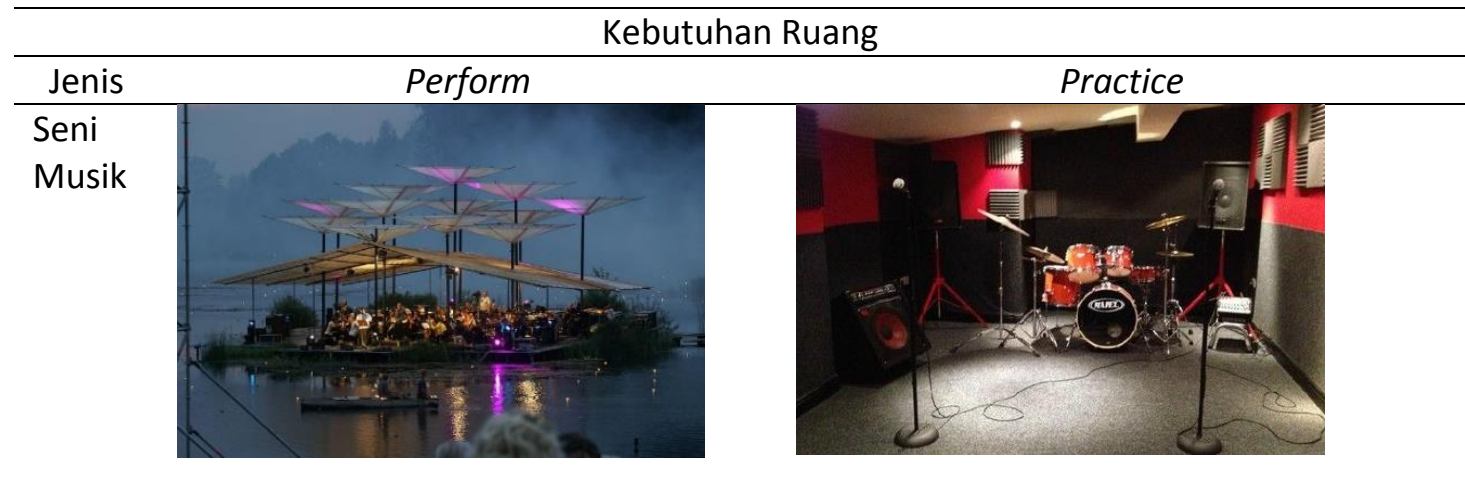

Space untuk alat musik pada panggung, audience berdiri atau duduk. Penggunaan stage atau tribun.

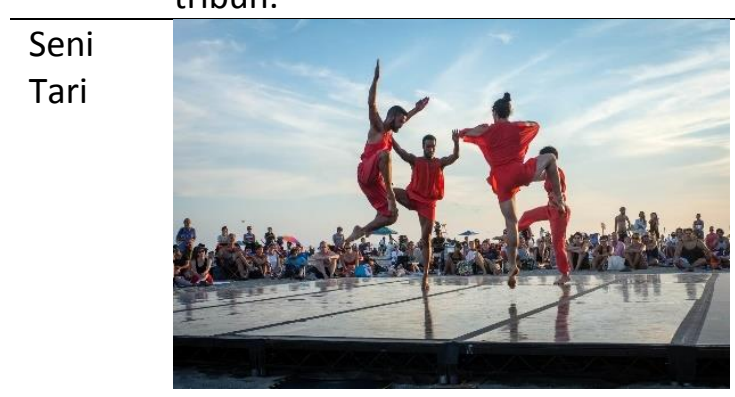

Stage one side view, 180 derjat, rounded (360 derajat).

Floor dance atau panggung

Audience tribun, rounded, atau duduk di lantai.

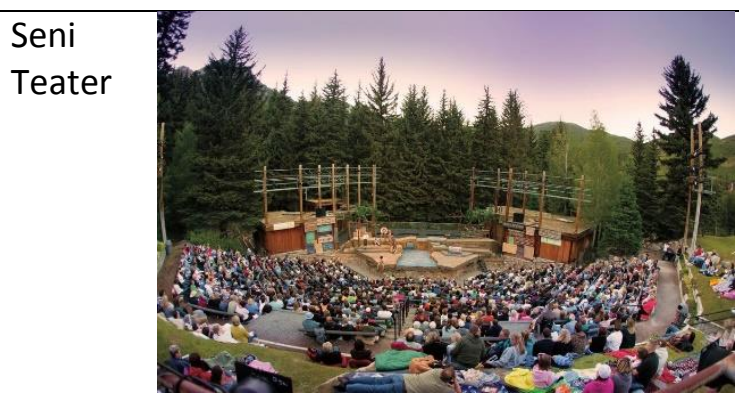

Penggunaan panggung dan tribun, dibutuhkan ruang properti pada panggung.
Ruang kedap suara, space untuk alat musik.

Kapasitas <

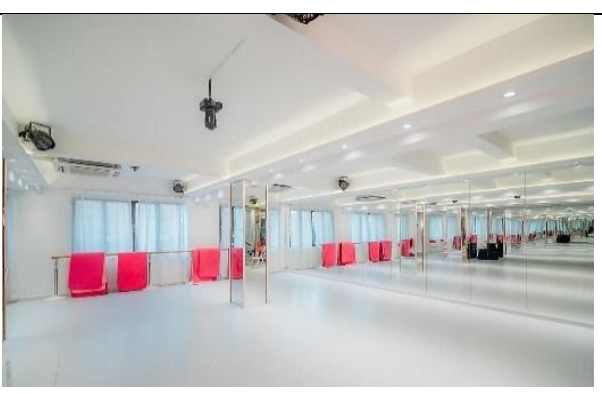

Ruang kosong dikelilingi kaca, permukaan lantai tidak licin. Kapasitas >

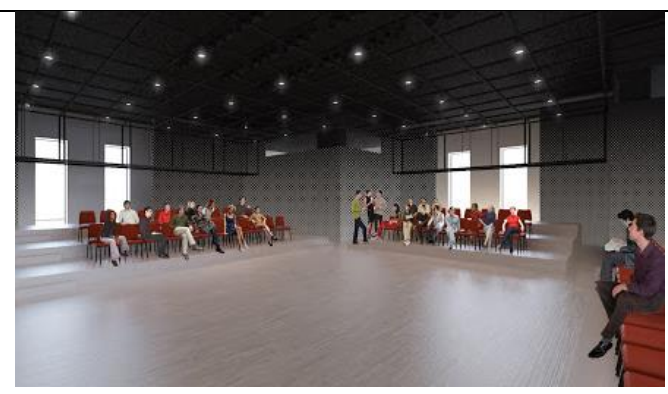

Ruang kososng dikelilingi mini tribun. Workshop property.

Kapasitas > 


\section{METODE}

Metode perancangan yang digunakan dalam perancangan ini :

a. Studi Literatur

Sebagai dasar teoritis untuk dasar konsep pemikiran; Mengetahui urban fabric yang membangun kota; Mengetahui standar yang terkait perancangan ruang kota

b. Studi preseden

Sebagai pembanding antara proyek; Mengerti standar yang dipakai proyek yang dijadikan sebagai preseden

c. Pengamatan lingkungan

Lokasi: lokasi sekitar kawasan Senen; Waktu: Siang hingga malam hari, Pukul 14:00 - 21:00

d. Metode pengamatan: Survey lapangan dan Pengambilan foto

\section{Metode desain Site Analysis}

Dalam merancang untuk mendapatkan gubahan dan form bangunan, digunakan metode site analysis agar bangunan memperhatikan konteks sekitar sehingga memperkuat konsep kontekstual.

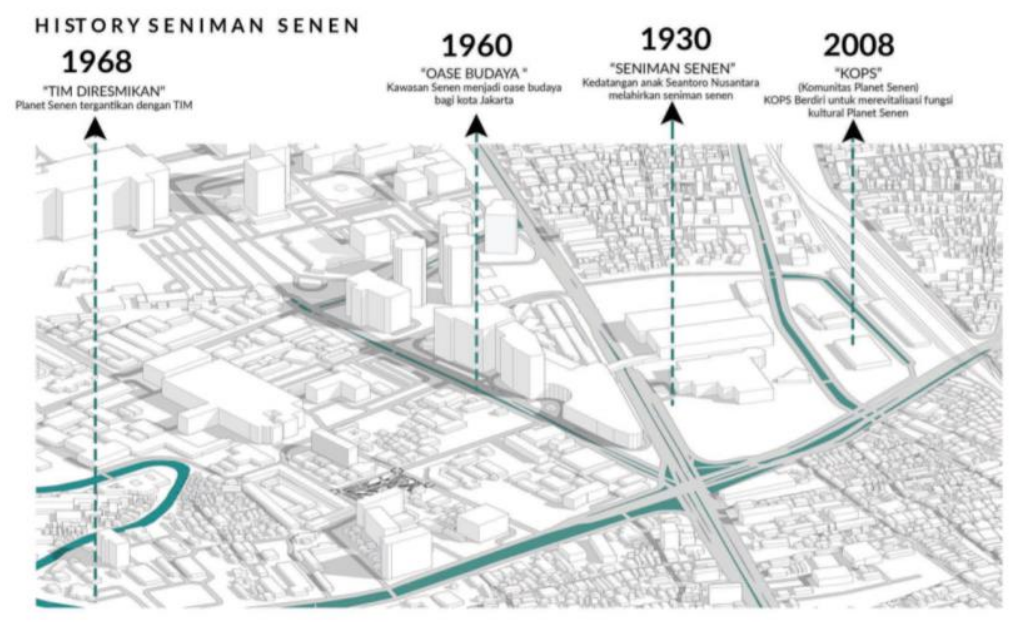

Gambar 1. Timeline Sejarah Seniman Senen Sumber:Penulis, 2020

Gambar 1 menjelaskan sejarah seniman kawasan Senen sejak tahun 1930. Senen pernah menjadi oase budaya bagi kota Jakarta dan melahirkan banyak seniman, diilihat dari hal tersebut kawasan senen dahulu memiliki karakteristik dan keterlibatan yang kuat terhadap seni.

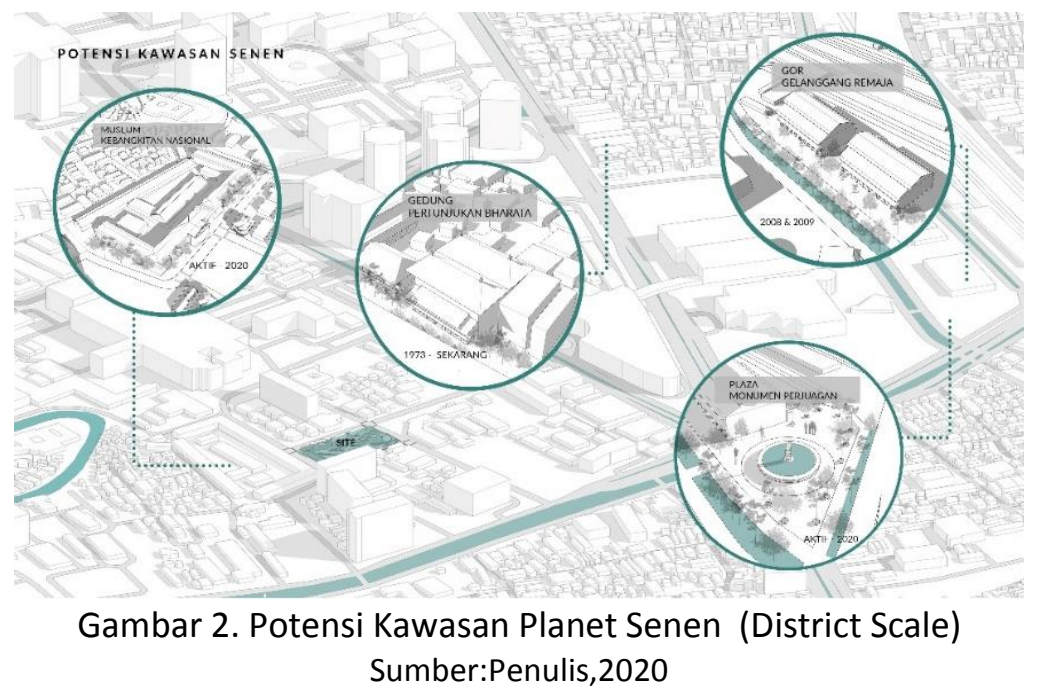


Gambar 2 Menjelaskan Potensi tapak diperkuat dengan adanya beberapa tempat kesenian dan kegitan seni yang masih aktif hingga saat ini. Dilansir dari Kemendikbud animo masyarakat Senen terhadap kegiatan seni masih sangat tinggi.

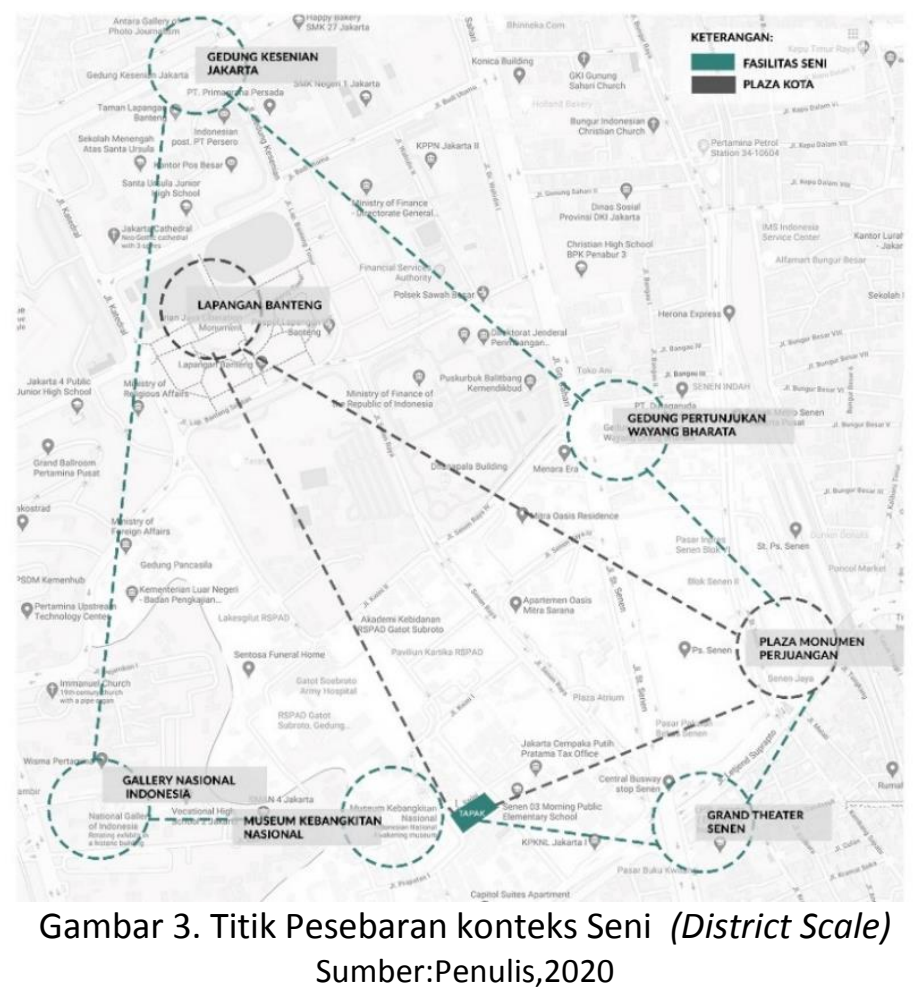

Gambar 3 menjelaskan penyebaran konteks seni pada kawasan senen, Lingkaran bewarna abuabu menunjukkan area ruang terbuka hijau kota, lingkaran berwarna hijau menunjukkan area seni. Dengan identifikasi tersebut kawasan memiliki potensi menciptakan proyek untuk mewadahi dan mendukung seniman yang ada pada kawsan Senen.

\section{DISKUSI DAN HASIL}

\section{Program}

Salah satu strategi desain proyek Art Space diterapkan pada pembagian fasilitas program berupa practice studio, practice space, dan plaza. Practice studio mewadahi seniman professional dengan fasilitas yang lengkap berupa studio teater, studio tari dan studio musik. Namun, tidak hanya untuk seniman professional practice space juga disediakan sebagai wadah eksplorasi dan mengembangan diri untuk para pencinta seni dan penikmat seni. Plaza dan Communal space hadir sebagai tempat netral untuk meeting point masyarakat setempat (khalayak umum). Pembagian tersebut didasari atas jenis dan kebutuhan pengunjung, dengan poin tersebut diharapkan proyek ini dapat bersifat inklusif yang akan mewadahi semua kalangan dan melahirkan interaksi sosial. 


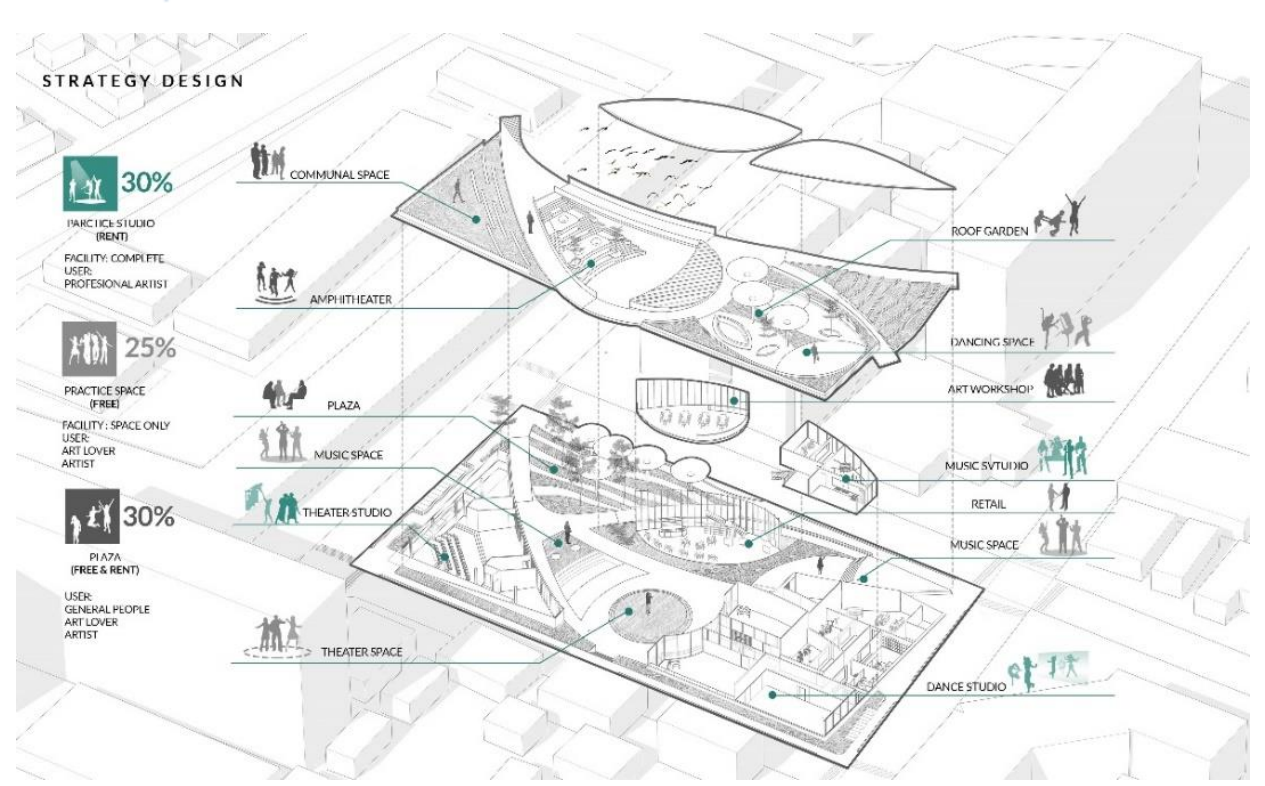

Gambar 4. Program Ruang

Sumber:Penulis, 2020

\section{Tapak}

Tapak terpilih berada di Jalan Abdul Rachman II, Senen, Jakarta Pusat. Tapak ini dipilih karena memenuhi kriteria tapak yaitu: Terletak pada kawasan yang memiliki titik seni yang kuat, tapak mudah dijangkau dan aksesibilitas tinggi.

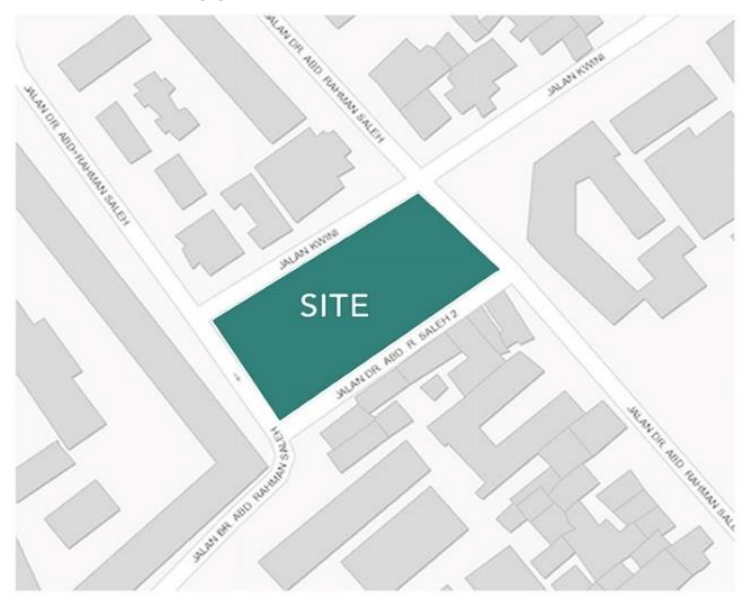

Gambar 5. Tapak Tepilih

Sumber:JakartaSatu.go.id

Dari sisi utara, selatan, barat, dan timur tapak berbatasan langsung dengan jalan raya hal ini membuat tapak dapat diakses dari segala arah. Tapak ini berjarak hanya enam meter dari Museum Kebangkitan Nasional, sehingga berpotensi untuk menarik pendatang dengan orientasi pedestrian.

\section{Konsep}

Dilihat dari segi konteks skala tapak, kawasan sekitar tapak dikelilingi bangunan solid sehingga menimbulkan kesan padat. Maka dari itu desain bangunan akan menghadirkan "void" di tengah kepadatan dan menjadi ruang terbuka publik serta meeting point bagi masyarakat sekitar. Memanfaatkan Museum Kebangkitan Nasional dan Sekolah Dasar Negri Senen 03 Pagi sebagai anchor membawa flow pedestrian kedalam tapak untuk menciptakan sirkulasi mikro yang dinamis. Menurunkan bangunan dan menghadirkan ruang hijau untuk membuat kesan 
void pada lingkungan sekitar. Penempatan program dengan meletakan area latihan pada bagian terluar dan art performance pada bagian tengah agar menciptakan focal point pada bangunan.
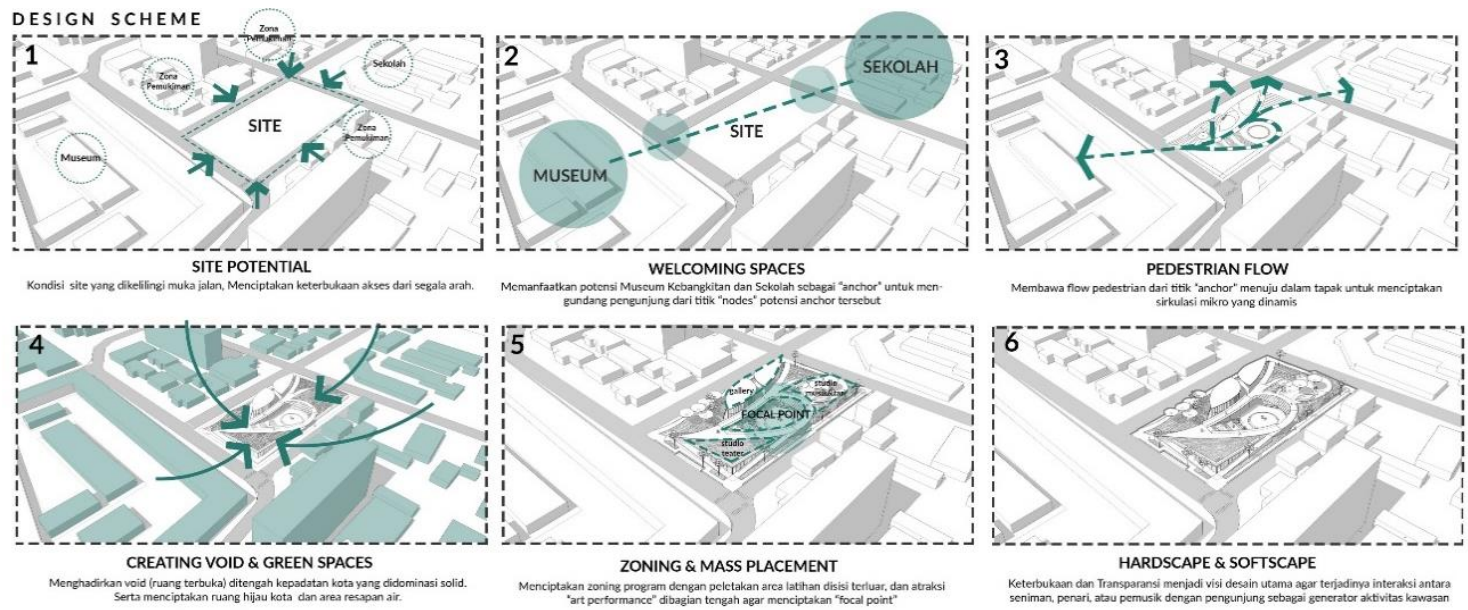

Gambar 6. Proses gubhana massa Sumber:Penulis, 2020

Dengan visi bluring boundery opensess and closeness konsep transparan diterapkan pada bangunan, Hal ini bertujuan untuk menghidupkan suasana seni bagi siapapun yang melewatinya dengan memperlihatkan aktivitas seni pada bangunan.

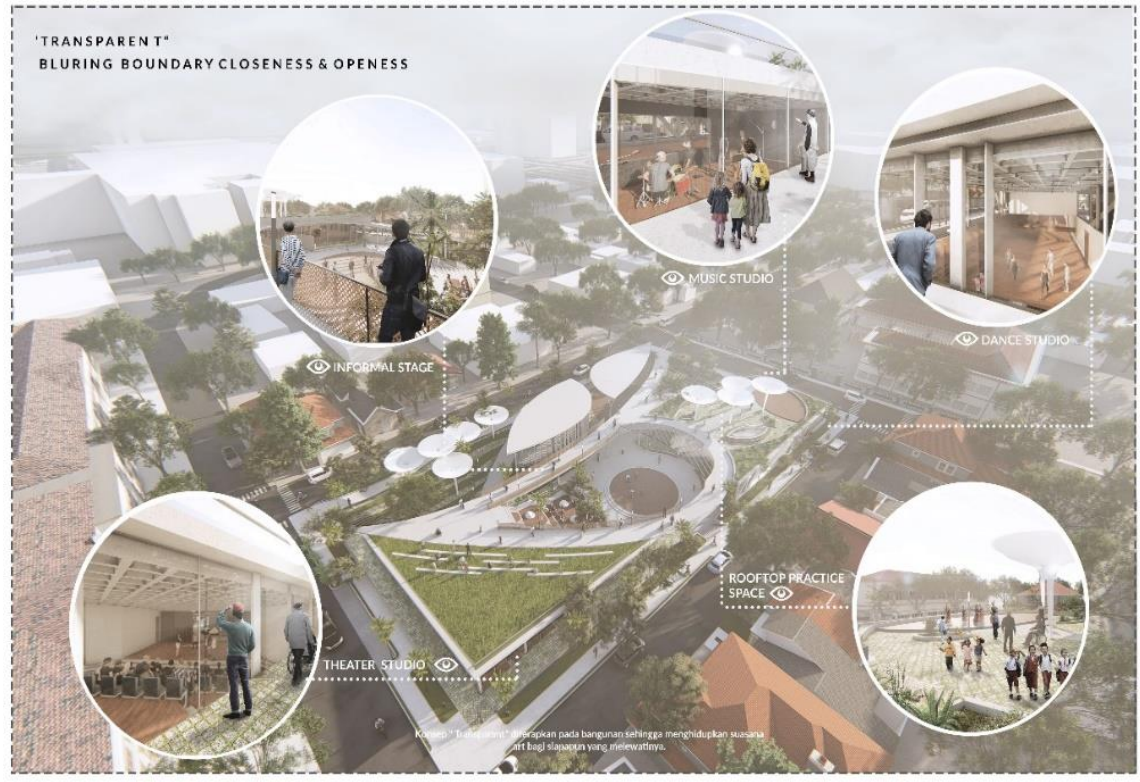

Gambar 7. Tranparansi Konsep

Sumber:Penulis, 2020

\section{KESIMPULAN DAN SARAN}

\section{Kesimpulan}

Berangkat dari issue hilangnya third place pada kota Jakarta, menjamurnya pusat gimmick market dan komersil menyebabkan turunnya tingkat interaksi sosial antara sesama manusia sehingga terbentuklah eksklusifitas pada setiap individu. Proyek Art Space mengangkat topik seni yang merupakan salah satu karakteristik kawasan kelurahan Senen, Senen, Jakarta Pusat. Seni akan digunakan sebagai media dan alat untuk berinteraksi serta berkomunikasi antara 
sesama manusia. Menjadikan pusat hiburan seni yang inklusif sehingga dapat dinikmati oleh seluruh golongan masyarakat baik seniman, penikmat seni atau khalayak umum. Pemilihan jenis seni pertunjukan didasarkan oleh tingginya animo masyarakat pada Kelurahan Senen. Perancangan Art Space didesain dengan mengkombinasikan tipologi yang diadaptasi dari kebiasaan atau pendekatan kebutuhan masyarakat sekitar. Meleburkan batasan diantara private closeness dan public opensess dengan skema transpansi yang akan menciptakan dialog antara seniman dan penikmat seni. Kehadiran ini dibuat untuk mewadahi komunitaskomunitas. Dengan menggunakan sistem hijau pada perancangan untuk pembangunan yang berkelanjutan. Konsep seni dalam mengembangkan potensi pada setiap individu didukung dengan program utama berupa practice space dan practice studio sehingga setiap individu dapat lebih mengeksplor diri dalam bidang seni. Serta konsep 'void' pada bangunan, membuat keserasian dengan lingkungan. Diharapkan proyek ini dapat menarik masyarakat untuk berkunjung sehingga menghadirkan interaksi diantara mereka.

\section{REFERENSI}

Dinas Kependudukan dan Pencatatan Sipil. (2019). Jakarta Open Data. Retrieved September 18, 2019, from http://data.jakarta.go.id

Dolley, J. (2019). Rethinking third places. Cheltenham: Edward Elgar Publishing.

Eisenman, P. (2001). The diagram process method: the design of architectural form.

McLaren, D., Agyeman, J. (2015). Cities: a case for truly smart and sustainable cities. MIT press.

Mukitnas. (2020). Belajar Tari Lintas Generasi di Museum Kebangkitan Naional. Retrieved February 18, 2020, from Kemendikbud, https://kebudayaan.kemdikbud.go.id

Oldenburg, R. (1999). The great good place. Cambridge: Da Capo Press.

Oldenburg, R. (2009). Celebrating the third place: inspiring stories about the great good places. US: Marlowe \& Company.

Seputar IImu. (2020). Macam-Macam Seni. Retrieved July 10, 2020, from https://seputarilmu.com/macam-macam-seni.

Shahab, A. (2002). Betawi: queen of the east. Republika.

Sumardjo, J. (2001). Seni pertunjukan Indonesia. Bandung: STSI Press

Wikipedia. (2017). History Kawasan Senen. Retrieved June 21, 2017, from https://en.wikipedia.org/wiki/Senen

Winata, S. (2020). Open architecture as the third place. Jakarta Barat, DKI Jakarta, Indonesia. 
